Document downloaded from:

http://hdl.handle.net/10251/57059

This paper must be cited as:

Robles Martínez, A.; Ruano García, MV.; Ribes Bertomeu, J.; Seco Torrecillas, A.; Ferrer, J. (2013). Mathematical modelling of filtration in submerged anaerobic MBRs (SAnMBRs): long-term validation. Journal of Membrane Science. 446:303-309. doi:10.1016/j.memsci.2013.07.001.

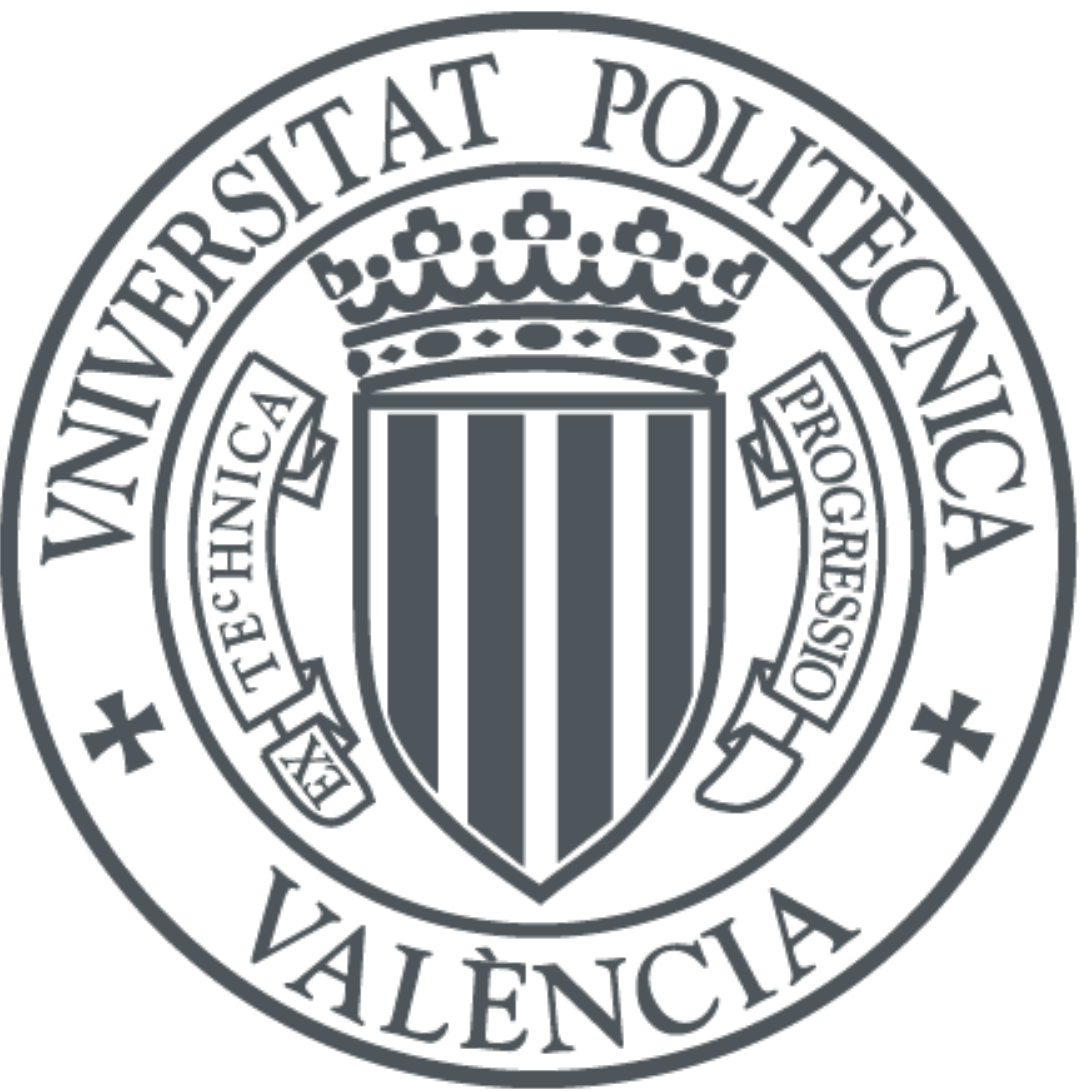

The final publication is available at

http://dx.doi.org/10.1016/j.memsci.2013.07.001

Copyright Elsevier

Additional Information 


\title{
Mathematical modelling of filtration in submerged anaerobic MBRs (SAnMBRs): long-term validation
}

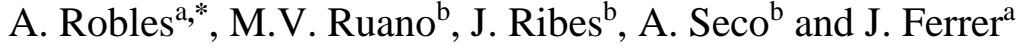 \\ a Institut Universitari d'Investigació d'Enginyeria de l'Aigua i Medi Ambient, IIAMA, \\ Universitat Politècnica de València, Camí de Vera s/n, 46022 Valencia, Spain (e-mail: \\ ngerobma@upv.es; jferrer@hma.upv.es) \\ b Departament d'Enginyeria Química, Escola Tècnica Superior d'Enginyeria, Universitat de \\ València, Avinguda de la Universitat s/n, 46100 Burjassot, Valencia, Spain (e-mail: \\ m.victoria.ruano@uv.es; josep.ribes@uv.es; aurora.seco@uv.es) \\ * Corresponding author: tel. +34 9638799 61, fax +34 9638790 09, e-mail: \\ ngerobma@upv.es
}

\begin{abstract}
The aim of this study was the long-term validation of a model capable of reproducing the filtration process occurring in a submerged anaerobic membrane bioreactor (SAnMBR) system. The proposed model was validated using data obtained from a SAnMBR demonstration plant fitted with industrial-scale hollowfibre membranes. The validation was carried out using both lightly and heavily fouled membranes operating at different bulk concentrations, gas sparging intensities and transmembrane fluxes. Across a broad spectrum of operating conditions, the model correctly forecast the respective experimental data in the long term. The simulation results revealed the importance of controlling irreversible fouling in order to ensure sustainable long-term membrane performance.
\end{abstract}

\section{Keywords}

Industrial-scale hollow fibre modules; long-term validation; resistance in series; filtration model; submerged anaerobic membrane bioreactor

\section{Highlights}


A filtration model for SAnMBRs has been validated using long-term data.

The model was validated for lightly and heavily fouled full-scale HF membranes.

Different MLTS levels, gas sparging intensities and permeate fluxes were applied.

The model reproduced the experimental data accurately.

\section{Introduction}

Understanding and optimising a complex system such as a membrane bioreactor $(\mathrm{MBR})$ is a difficult and time-consuming process mainly because of the large number of sub-processes taking place simultaneously, which generally are highly dependent upon each other. In this regard, mathematical modelling is a powerful tool for studying such complex systems [1].

Certain models have been found to be useful for different objectives related to wastewater treatment plants (WWTPs) such as the research and development of wastewater treatment processes, the design and upgrading of WWTPs, and development of operating and control strategies designed to optimise process performance [2, 3, 4]. Computerised models make it possible to perform many virtual experiments in a short space of time. Therefore the mathematical modelling of filtration in submerged anaerobic MBRs (SAnMBRs) may help gain insights into the key factors in membrane fouling [5], and are also invaluable for the design, prediction and control of membrane technology used for treating wastewater [6]. In this regard, good modelling practices must guarantee adequate calibration/validation results not only in the short term but also in the long term.

One key issue as regards the long-term validation of a SAnMBR filtration model is the lack of data gathered from full-scale facilities, especially those treating urban 
wastewater. Specifically, there is still a lack of knowledge about irreversible membrane fouling mechanisms in the long term. Thus, there is a need for further research into the long-term performance of industrial-scale membranes in SAnMBRs dealing with urban wastewater in order to accurately validate a filtration model applied to this technology.

In a previous study, on the basis of the experimental results obtained whilst operating a SAnMBR plant fitted with industrial-scale hollow-fibre (HF) membranes, we developed a mathematical model capable of reproducing filtration in SAnMBRs [7]. This filtration model is based on the resistance-in-series modelling concept and can easily be linked to biological models. The proposed model takes into account the effect of the shear intensity in the membrane tank caused by the biogas recycling flow. Thus, the membrane scouring process occurring during the different membrane module operating stages (filtration, relaxation...) can be reproduced. The physical processes considered in this model are: cake layer build-up and compression during filtration; cake layer removal using biogas sparging to scour the membrane; cake layer removal during back-flushing; and the consolidation of irreversible fouling.

The aim of the present study was to validate the above-mentioned filtration model in the long-term under different operating conditions. Once validated, the possibilities of applying this model to the development of different operating and control strategies designed to optimise membrane performance and lifespan were assessed. In order to obtain robust results that could be extrapolated to full-scale applications, the model was validated using long-term data from a SAnMBR plant fitted with industrial-scale HF membranes.

\section{Materials and methods}




\subsection{SAnMBR plant description}

The model was validated in the long term using data from a demonstration-scale SAnMBR system. The plant consists of an anaerobic reactor with a total volume of 1.3 $\mathrm{m}^{3}$ connected to two membrane tanks each with a total volume of $0.8 \mathrm{~m}^{3}$. Each membrane tank has one industrial HF ultrafiltration membrane unit $\left(\mathrm{PURON}^{\circledR}\right.$, Koch Membrane Systems (PUR-PSH31) with $0.05 \mu \mathrm{m}$ pores). Each module has a total membrane surface of $30 \mathrm{~m}^{2}$. For further details of this SAnMBR system, see Robles et al. [8].

2.2. On-line and analytical monitoring

To account for the dependence of permeate viscosity on temperature $(\mathrm{T})$, the gross $20^{\circ} \mathrm{C}$-normalised transmembrane flux $\left(J_{20}\right)$ was calculated from the on-line monitored temperature and gross transmembrane flux $\left(J_{T}\right)$ using Eq. 1.

$$
J_{20}=J_{T} \cdot \exp (-0.0239(T-20))
$$

In addition to being monitored on line (Hach Lange model TSS EX1 sc), a grab sample of anaerobic sludge was taken once a day to determine the mixed liquor total solids (MLTS) concentration according to Standard Methods [9]. The mixed liquor volatile solids (MLVS) of the anaerobic sludge was also analysed each day.

Extracellular polymeric substances (EPS) and soluble microbial products (SMP) 
were extracted and measured once a week. Mixed liquor was collected from the system and a sample of $150 \mathrm{~mL}$ was centrifuged at $2000 \mathrm{xG}$ for $15 \mathrm{~min}$ at $4{ }^{\circ} \mathrm{C}$ (Eppendorf Centrifuge 5804R). The supernatant was filtered using a $1.2 \mu \mathrm{m}$ filter and the SMP levels $\left(\mathrm{SMP}_{\mathrm{C}}\right.$ and $\mathrm{SMP}$, related to carbohydrates and proteins respectively) were measured. The EPS was extracted according to the Cation Exchange Resin (CER) method proposed by Frølund et al. [10]. The sludge pellets were resuspended to their original volume using a buffer consisting of $2 \mathrm{mM} \mathrm{Na}_{3} \mathrm{PO}_{4}, 4 \mathrm{mM} \mathrm{NaH}_{2} \mathrm{PO}_{4}, 9 \mathrm{mM}$ $\mathrm{NaCl}$ and $1 \mathrm{mM} \mathrm{KCl}$ at $\mathrm{pH}$ 7. EPS was extracted as follows: $100 \mathrm{~mL}$ of the suspension was transferred to an extraction container and $70 \mathrm{~g} / \mathrm{g}$ MLVS of CER were added; the suspension was stirred at the selected intensity $(900 \mathrm{rpm})$ and extraction time (20 hours)

at $4{ }^{\circ} \mathrm{C}$. The extracted EPS was harvested by centrifuging the CER/sludge suspension for 15 min at $12000 \mathrm{xG}$ and $4{ }^{\circ} \mathrm{C}$ to remove the CER and MLTS. The supernatant was then filtered with a $1.2 \mu \mathrm{m}$ filter and the extracted EPS levels $\left(\mathrm{eEPS}_{\mathrm{C}}\right.$ and eEPS , related to carbohydrates and proteins respectively) were measured. The carbohydrates and proteins of both SMP and eEPS were determined by colorimetry according to the methodology proposed by Dubois et al. [11] and Lowry et al. [12] respectively. Bovine serum albumin (BSA) and glucose were used as protein and carbohydrate standards respectively.

\subsection{Model description}

The filtration model used in this study aims at reproducing the main processes that occur during filtration in SAnMBRs: cake layer build-up and compression; sub-critical fouling; membrane scouring by biogas sparging; removal of cake layer by backflushing; and irreversible fouling consolidation. To this aim, the model, which is based on the resistance-in-series modelling concept, was developed using the experimental 
results obtained from a SAnMBR plant fitted with industrial-scale HF membranes. The cake layer compression process during filtration is reproduced by considering that the average specific cake resistance, $\alpha_{\mathrm{C}}\left(\mathrm{m} \mathrm{kg}^{-1}\right)$, is time and TMP dependent. Moreover, the model tries to reproduce the specific fouling mechanisms related to sub-critical fouling (e.g. colloidal matter absorption) by increasing $\alpha_{\mathrm{C}}$ over time. On the other hand, a blackbox approach was proposed for describing the following physical interactions occurring in fouling (reversible and irreversible): attachment of solids to the membrane surface during filtration; removal of solids from the membrane surface due to membrane scouring and back-flushing; and irreversible fouling of the membrane.

\subsubsection{Resistance-in-series model}

The proposed model represents the dynamic evolution of the transmembrane pressure (TMP) by applying Eq. 2 and Eq. 3.

$$
T M P(t)=J \cdot \mu \cdot R_{T}
$$

Where:

- $\quad J$ is the transmembrane flux $\left(\mathrm{m} \mathrm{s}^{-1}\right)$

- $\quad \mu$ is the permeate dynamic viscosity $\left(\mathrm{kg} \mathrm{m}^{-1} \mathrm{~s}\right)$

- TMP (t) is the TMP at time $t(\mathrm{~Pa})$

- $R_{T}$ is the total filtration resistance $\left(\mathrm{m}^{-1}\right)$

$$
R_{T}=R_{M}+R_{C}+R_{I}=R_{M}+\omega_{C} \cdot \alpha_{C}+\omega_{I} \cdot \alpha_{I}
$$

Where:

- $R_{M}$ is the intrinsic membrane resistance $\left(\mathrm{m}^{-1}\right)$ 
- $R_{C}$ is the cake layer resistance $\left(\mathrm{m}^{-1}\right)$

- $\quad R_{I}$ is the irreversible fouling resistance $\left(\mathrm{m}^{-1}\right)$

- $\quad \omega_{C}$ is the mass of cake deposited per membrane area $\left(\mathrm{kg} \mathrm{m}^{-2}\right)$

- $\quad \omega_{I}$ is the mass of irreversible fouling per membrane area $\left(\mathrm{kg} \mathrm{m}^{-2}\right)$

- $\quad \alpha_{I}$ is the average specific irreversible fouling resistance $\left(\mathrm{m} \mathrm{kg}^{-1}\right)$

\subsubsection{Cake layer compression and sub-critical fouling}

To account for the cake layer compression process, $\alpha_{C}$ was defined as both time and TMP dependent (see second term in the max function of Eq. 4), as per Bugge et al. [13] and Jørgensen et al. [14]. It allowed accounting for the cake compression due to both the deformation of soft sludge flocs and the structural rearrangement of particles [15]. In addition, to account for sub-critical fouling, an additional dependence of $\alpha_{C}$ on time was considered in the model [7] (as expressed by the first term in the max function of Eq. 4). It allowed accounting for colloidal matter absorption increasing the specific resistance of cake-like deposits [16]. In our model, we propose that when the maximum $\alpha_{C}$ related to the structural rearrangement of particles is reached at a given TMP (see second term in the max function of Eq. 4), it is possible to account for the increase in $\alpha_{C}$ due to the absorption of colloids (first term in the max function of Eq. 4), as expressed by Eq. 4 below. For further details of the application of Eq. 4 see Robles et al. [7].

$\alpha_{C}(t)=\alpha_{C}(t-\Delta t)+\max \left(k_{S F}, k_{t} \cdot\left(\alpha_{C, 0} \cdot\left(1+\frac{T M P}{T M P_{a}}\right)-\alpha_{C}(t-\Delta t)\right)\right) \cdot \Delta t$

Where:

- $\quad \alpha_{C}(t)$ is the specific resistance of the cake at time $t\left(\mathrm{~kg} \mathrm{~m}^{-2}\right)$. 
- $\quad \alpha_{C}(t-\Delta t)$ is the specific resistance of the cake at a previous moment in time $(\mathrm{kg}$ $\left.\mathrm{m}^{-2}\right)$.

- $\quad k_{S F}$ is the parameter related to sub-critical fouling $\left(\mathrm{kg} \mathrm{m}^{-2} \mathrm{~s}^{-1}\right)$.

- $\quad \alpha_{C, 0}$ is the specific resistance of the cake at zero pressure $\left(\mathrm{kg} \mathrm{m}^{-2}\right)$

- $\quad T M P_{a}$ is the pressure needed to double the specific resistance $(\mathrm{Pa})$

- $\quad k_{t}$ is the time constant $\left(\mathrm{s}^{-1}\right)$.

- $\Delta \mathrm{t}$ is the time step (s).

\subsubsection{Black-box approach}

For describing the above-mentioned physical interactions affecting TMP (cake layer build-up; removal of solids from the membrane surface due to membrane scouring and back-flushing; and irreversible fouling of the membrane), the variations on $\omega_{C}$ and $\omega_{I}$ must be considered. A black-box approach for modelling the dynamics of $\omega_{C}$ and $\omega_{I}$ is proposed in the model. The black-box approach considers 3 suspended components: MLTS concentration, $X_{T S}\left(\mathrm{~kg} \mathrm{~m}^{-3}\right)$; dry mass of cake over the membrane surface, $X_{m_{C}}$ $(\mathrm{kg})$; and dry mass of irreversible fouling over the membrane surface, $X_{m_{I}}(\mathrm{~kg})$.

This model considers a total of four kinetic physical processes: (1) cake layer buildup during filtration; (2) cake layer removal using biogas sparging to scour the membrane; (3) cake layer removal during back-flushing; and (4) irreversible fouling consolidation. The model does not consider diffusive back transport as this process is thought to be less significant than the other processes considered [17]. Table 1 shows the stoichiometry and the kinetic expressions of the four processes considered in the model. 
Process 1 (cake layer build-up) is the convective transport of foulants ( $X_{T S}$ in the model) to the membrane, which is a function of permeate flow, $Q_{20 P}\left(\mathrm{~m}^{3} \mathrm{~s}^{-1}\right)$, and $X_{T S}$. Process 2 (membrane scouring by biogas sparging) is the impact of the hydrodynamic conditions in the membrane tank caused by biogas sparging (measured as BRFv: biogas recycling flow per bulk volume in the membrane tank). In our study, a maximum membrane scouring velocity $\left(q_{M S, M a x}\right)$ was defined for process 2 . In process 3 , the backflushing removal rate is defined as a function of the back-flushing flow rate, $Q_{20 B F}\left(\mathrm{~m}^{3}\right.$ $\mathrm{s}^{-1}$ ), and $X_{m_{C}}$. Like Sarioglu et al. [17], we defined a maximum back-flushing removal velocity for process $3, q_{B F, \operatorname{Max}}\left(\mathrm{m}^{-3}\right)$.

One half-saturation switching function $\left(M_{X_{m_{C}}}\right.$, Eq. 5) for both membrane scouring (process 2) and back-flushing (process 3) was used to gradually decrease the removal rate of solids as the cake layer disappeared [17].

$$
M_{X_{m_{C}}}=\frac{X_{m_{C}}}{K_{S, X_{m_{C}}}+X_{m_{C}}}
$$

Where:

- $\quad K_{S, X_{m_{C}}}$ is the half-saturation coefficient of the mass of cake solids during membrane scouring and back-flushing $\left(\mathrm{kg} X_{m_{C}}\right)$.

Process 2 includes one sigmoid inhibition function ( $I_{M S}$, Eq. 6) to model the impact of filtering at conditions above or below critical levels. This sigmoid inhibition function 
was first defined in Robles et al. [7], on the basis of the results obtained from different flux-step trials conducted in accordance with Robles et al. [18].

$$
I_{M S}=\frac{1}{1+K_{F} \cdot e\left(J_{20} \cdot\left(\beta_{1} \cdot B R F_{V}+\beta_{1} \cdot M L T S+\gamma\right)\right)}
$$

Where:

- $\quad K_{F}$ is the adjustment parameter representing the fouling rate when $\left(J_{20}\right.$ tends to zero $\left(\mathrm{Pa} \mathrm{s}^{-1}\right)$.

- $\quad \beta_{1}\left(\mathrm{~s}^{2} \mathrm{~m}^{-1}\right), \beta_{2}\left(\mathrm{~s} \mathrm{~m}^{2} \mathrm{~kg}^{-1}\right), \gamma\left(\mathrm{s} \mathrm{m}^{-1}\right)$ are the model parameters.

On the basis of long-term experimental results, the value of $\gamma$ was defined as a function of $R_{I}$ to account for the gradual reduction in the filtering capacity of the membranes due to irreversible fouling. This dependence on irreversible fouling can be expressed as:

$\gamma_{t}=\gamma_{0}-\left(R_{I_{t}}-R_{I_{0}}\right) k_{R I}$

Where:

- $\gamma_{t}$ is the value of $\gamma$ at time $t\left(\mathrm{~s} \mathrm{~m}^{-1}\right)$.

- $\quad \gamma_{0}$ is the value of $\gamma$ at the initial time $\left(\mathrm{s} \mathrm{m}^{-1}\right)$.

- $\quad R_{I_{t}}$ is the irreversible fouling resistance at time $t\left(\mathrm{~m}^{-1}\right)$.

- $\quad R_{I_{0}}$ is the irreversible fouling resistance at the initial time $\left(\mathrm{m}^{-1}\right)$.

- $\quad k_{R I}$ is the proportional constant (s). 
Finally, the irreversible fouling (process 4) is represented in the proposed model as a direct function of $X_{m_{C}}$ and a maximum irreversible fouling kinetic constant, $q_{I F, \operatorname{Max}}\left(\mathrm{s}^{-}\right.$ $\left.{ }^{1}\right)$.

The parameters used in this filtration model were calibrated in a previous study by off-line and dynamic calibration methods using short-term and long-term data (see Robles et al. [7]). Table 2 shows the previously calibrated values, which have been used in this study with no further adjustment. For further details of this filtration model see Robles et al. [7].

\subsection{Long-term model validation}

The filtration model used in this study was previously calibrated using both shortand long-term data obtained from the SAnMBR plant mentioned earlier [7]. The calibrated values of the different parameters included in the model are shown in Table 2. In this study we have validated the model in the long-term using both heavily-fouled and lightly-fouled membranes. The data needed to validate the model was also obtained from said SAnMBR plant. The long-term validation using heavily-fouled membranes comprised an operating period of 180 days, whilst the long-term validation using lightly-fouled membranes comprised an operating period of 140 days. Both validations aimed to demonstrate the capability of the proposed model to reproduce filtration in SAnMBRs even when operating under quite different dynamic operating conditions (i.e. using heavily-fouled and lightly-fouled membranes).

The average daily operating conditions applied during the long-term model validation using heavily-fouled membranes were as follows: sludge retention time 
(SRT) of 38.5 days, average operating temperature of $20^{\circ} \mathrm{C}$, MLTS levels from 15 to 25 $\mathrm{g} \mathrm{L}^{-1}$, specific gas demand per square metre of membrane ( $\left.\mathrm{SGD}_{\mathrm{m}}\right)$ from 0.13 to 0.46 $\mathrm{Nm}^{3} \mathrm{~h}^{-1} \mathrm{~m}^{-2}$ and net $20{ }^{\circ} \mathrm{C}$-normalised transmembrane flux $\left(J_{20 n e t}\right)$ from 2.5 to $12 \mathrm{LMH}$. The average daily operating conditions applied during the long-term model validation using lightly-fouled membranes were as follows: SRT of 71.5 days, average operating temperature of $33{ }^{\circ} \mathrm{C}$, MLTS levels from 7 to $25 \mathrm{~g} \mathrm{~L}^{-1}$, SGD controlled at $0.23 \mathrm{Nm}^{3} \mathrm{~h}^{-1}$ $\mathrm{m}^{-2}$ and $J_{20 n e t}$ of approx. 8 and $11 \mathrm{LMH}$.

It must be emphasised that both long-term validations were conducted at different SRT and T, therefore different propensities to irreversible fouling were expected. However, the value of $q_{I F, \operatorname{Max}}$ remained the same in both instances, resulting in acceptable results. This was mainly attributed to the presence of similar amounts of SMP and EPS in the mixed liquor (around $150-180 \mathrm{mg} \mathrm{g}^{-1}$ MLVS and $60-80 \mathrm{mg} \mathrm{g}^{-1}$ MLVS, respectively). In this regard, SMP and EPS seem to be the main factors affecting irreversible fouling in MBRs [19], which are directly dependent on T [20] and SRT [21]. Usually, SMP and EPS decrease as SRT increases, whilst SMP and EPS increase as the temperature increases due to greater microbial activity. Therefore, $q_{I F, M a x}$ may be assumed to be a function of both T and SRT. In our study, since the operating period spanning the highest SRT (71.5 days) was conducted at the highest temperature $\left(33^{\circ} \mathrm{C}\right.$ ) and the period spanning the lowest SRT (38.5 days) was conducted at the lowest temperature $\left(20^{\circ} \mathrm{C}\right)$, it was expected that the impact of both SRT and T upon irreversible fouling would offset each other. For this reason, the same $q_{I F, \text { Max }}$ value was applied in both operating periods.

\section{Results and discussion}


3.1. Model validation using heavily-fouled membranes

As commented before, heavily-fouled membranes were used for validating the model when operating at SRT of 38.5 days and $20^{\circ} \mathrm{C}$. Figure 1a shows the daily average values for $J_{20 \text { net }}$ (ranging from 2.5 to $12 \mathrm{LMH}$ ) and $\mathrm{SGD}_{\mathrm{m}}$ (ranging from 0.13 to $0.46 \mathrm{Nm}^{3} \mathrm{~h}^{-1} \mathrm{~m}^{-2}$ ). Since, as we have already said, model validation was conducted using heavily-fouled membranes, the operating $J_{20 n e t}$ was very low. Figure $1 \mathrm{~b}$ shows the average daily values of the simulated and experimental TMP (TMP $\mathrm{SIM}_{\text {and }}$ TMP $\mathrm{EXP}_{\text {, }}$ respectively). As this figure shows, even when operating with variable $J_{20 n e t}$ and $\mathrm{SGD}_{\mathrm{m}}$ (see Figure 1a), the model was able to reproduce membrane performance correctly in the long term (see Figure 1b), resulting in an adequate Pearson Product-Moment correlation coefficient $(r)$ between TMP EXP $_{\text {and TMP }}$ SIM of 0.893 . Nevertheless, a slight deviation of TMP $\mathrm{TIM}_{\mathrm{SIM}}$ from TMP $\mathrm{EXP}$ was observed on operating days $67-73$. This deviation was attributed to the fact that no data was gathered on those days from the online biogas composition analyser needed to normalise the volumetric biogas recycling flow (the on-line biogas composition analyser was not available due to maintenance). To account for the dependence of volumetric biogas flow on biogas composition, $\mathrm{SGD}_{\mathrm{m}}$ was normalised using Eq. 4. On operating days $67-73$, the on-line biogas composition analyser was not available due to maintenance requirements. Therefore, the correction was not applied and lower $\mathrm{SGD}_{\mathrm{m}}$ values than the ones resulting from applying Eq. 4 were recorded (a reduction in the $\mathrm{SGD}_{\mathrm{m}}$ values on operating days 67 - 73 can be seen in Figure 1a). In this regard, the model would probably have predicted lower TMP SIM values than the ones shown on operating days $67-73$ (see Figure 1b) if the correctly corrected $\mathrm{SGD}_{\mathrm{m}}$ had been recorded (decreasing $\mathrm{SGD}_{\mathrm{m}}$ means increasing the amount of solids deposited on the membrane surface, which increases TMP). 
$S G D m_{\text {CORRECTED }}=S G D m_{M E A S U R E D} \cdot$ frho

Where:

$$
f r h o=\sqrt{\left(r h o_{C H 4} \cdot \% \mathrm{CH}_{4}+r h o_{\mathrm{CO} 2} \cdot \% \mathrm{CO}_{2}+r h o_{\mathrm{H} 2} \cdot \% \mathrm{H}_{2}+r h o_{\mathrm{H} 2 \mathrm{~S}} \cdot \% \mathrm{H}_{2} \mathrm{~S}+r h o_{\mathrm{N2}} \cdot \% \mathrm{~N}_{2}\right) / 100}
$$

- $\quad$ rho AIR: volumetric weight of air $\left(1.2930 \mathrm{~kg} \mathrm{~m}^{-3}\right)$

- $\quad r h o_{C H 4}$ : volumetric weight of $\mathrm{CH}_{4}\left(0.7168 \mathrm{~kg} \mathrm{~m}^{-3}\right)$

- rho $\mathrm{CO}_{2}$ : volumetric weight of $\mathrm{CO}_{2}\left(1.9768 \mathrm{~kg} \mathrm{~m}^{-3}\right)$

- $\quad r h o_{H 2}$ : volumetric weight of $\mathrm{H}_{2}\left(0.0449 \mathrm{~kg} \mathrm{~m}^{-3}\right)$

- $\quad r h o_{\text {H2S: }}$ volumetric weight of $\mathrm{H}_{2} \mathrm{~S}\left(1.5195 \mathrm{~kg} \mathrm{~m}^{-3}\right)$

- $r h o_{N 2}$ : volumetric weight of $\mathrm{N}_{2}\left(1.2505 \mathrm{~kg} \mathrm{~m}^{-3}\right)$

Figure 2a shows the average daily MLTS level (ranging from 15 to $25 \mathrm{~g} \mathrm{~L}^{-1}$ ), and the simulated average daily values for $\omega_{C}$ and $\omega_{I}$. The $R_{I}$ (determined as the difference between $R_{T}$ and $R_{M}$ during back-flushing) obtained from experimental data, gave an initial $\omega_{I}$ of $0.03 \mathrm{~kg} X_{m_{I}} \mathrm{~m}^{-2}$ (see Figure 2a). As it was expected (Figure 2a), the highest $\omega_{C}$ values occurred when operating at high $J_{20 n e t}$ (see operating days 60 - 75 in Figure 1a), which corresponds to the lowest $\operatorname{SGD}_{\mathrm{m}}\left(0.13-0.2 \mathrm{Nm}^{3} \mathrm{~h}^{-1} \mathrm{~m}^{-2}\right.$, see Figure 1a). This is the result of an increasing convective transport of foulants ( $X_{T S}$ in the model) from the bulk to the membrane surface, combined with weak shear conditions in the membrane tank due to a reduction in the biogas sparging intensity. On the contrary, a considerable decrease in $\omega_{C}$ (due to increasing the membrane scouring rate) was observed when $J_{20 n e t}$ fell from about 7 to $3 \mathrm{LMH}$ (see operating days 115 - 120 in Figure 1a). It must be emphasised that the membrane scouring velocity $\left(q_{M S}\right)$ is a function of an exponentialtype inhibition function that depends on both MLTS and $J_{20}$ (Eq. 6), which is used to model the effect of filtering below or above critical conditions [7]. It can, therefore, be assumed that the membranes were operated supra-critically on operating days $60-75$ 
and sub-critically on operating days $115-120$.

Irreversible fouling is represented in the model as a direct function of $X_{m_{C}}$. Therefore, $\omega_{C}$, which directly depends on $J_{20 n e t}$, was assumed to be one key factor that finally determines the irreversible fouling of the membranes. In this respect, high $\omega_{C}$ values resulting from operating at high $J_{20}$ values will result in a greater propensity to irreversible fouling than when operating at low $J_{20}$ values.

As Figure 2a shows, the highest irreversible fouling rate modelled $\left(0.0051 \mathrm{~kg} X_{m_{l}}\right.$ $\mathrm{m}^{-2} \mathrm{~d}^{-1}$ ) was reached on operating days $63-73$ (which coincides with the highest $\omega_{C}$ levels). In addition, a decrease in the irreversible fouling rate from 0.0015 to $0.0005 \mathrm{~kg}$ $X_{m_{I}} \mathrm{~m}^{-2} \mathrm{~d}^{-1}$ was observed (calculated on operating days $104-115$ and $120-131$, respectively) when $J_{20 n e t}$ decreased from about 7 to 3 LMH (see operating days 115 120 in Figure 1a): $\omega_{C}$ decreased from approx. 0.5 to $0.25 \mathrm{~kg} \mathrm{~m}^{-2}$. Apart from $J_{20 n e t}, \omega_{C}$ is also dependent on MLTS. Nevertheless, even when MLTS decreased from approx. 18.5 to $15 \mathrm{~g} \mathrm{~L}^{-1}$ on operating days 148 to 181 , the model predicted an increase in the irreversible fouling rate from 0.0006 to $0.0019 \mathrm{~kg} X_{m_{I}} \mathrm{~m}^{-2} \mathrm{~d}^{-1}$ (calculated on operating days $121-144$ and $148-179$, respectively) due to $J_{20 n e t}$ increasing from about 3 to 8 LMH (see operating days 145 - 150 in Figure 1a). The average irreversible fouling rate for the whole operating period (181 days of continuous operation) resulted in 0.00015 $\mathrm{kg} X_{m_{I}} \mathrm{~m}^{-2} \mathrm{~d}^{-1}$.

It must be emphasised that modelling $\omega_{C}$ may make it possible to optimise overall membrane performance in SAnMBR technology because it enables operating and control strategies designed to minimise cake layer formation to be tested and developed. 
Figure $2 \mathrm{~b}$ shows the simulated average daily values of $\alpha_{C}$. As this figure shows, $\alpha_{C}$ increased from approx. $2 \cdot 10^{13}$ to $25 \cdot 10^{13} \mathrm{~m} \mathrm{~kg}^{-1}$ when TMP increased from approx. 0.1 to 0.3 bar (see operating days $70-75$ in Figure $1 b$ ). Similar behaviour was observed on operating days $143-181$ (see Figure 1a), when TMP was $0.1-0.2$ bars. The considerable increase in $\alpha_{C}$ due to the increase in TMP highlights the need to model not only cake build-up but also cake compression in filtration processes of this type [13, 14].

Figure 3 a shows the average daily results (in absolute terms) of the simulation obtained at the different filtration resistances $\left(R_{T}, R_{M}, R_{C}\right.$ and $\left.R_{I}\right)$ considered in the model. As regards reversible fouling, Figure 3a shows a sharp increase in $R_{C}$ (and consequently in $R_{T}$ ) on operating days $60-75$, caused by the high values of $\omega_{C}$ and $\alpha_{C}$ observed (see Figure 2). Similar behaviour can be seen on operating days $141-181$. In this period it was assumed that the membranes were operated around or above the critical flux level, resulting in the accumulation of more solids on the membrane surface than when operating sub-critically (see, for example, operating days $1-41$ and $81-$ 141). As regards irreversible fouling, Figure 3 a shows a continuous increase in $R_{I}$ over time as a result of the continuous increase in $\omega_{I}$ (see Figure $2 a$ ).

Since it is possible to simulate $R_{I}$ and $R_{C}$ from the predicted $\omega_{C}$ and $\omega_{I}$ values, the weighted average daily distribution for $R_{T}$ can be modelled in the long-term (see Figure 3b). As Figure $3 b$ shows, a constant slightly decrease in the weighted average contribution of $R_{M}$ to $R_{T}$ is observed throughout the operating period mainly as a result of the increasing contribution of $R_{I}$ to $R_{T}$. On the other hand, the weighted average contribution of $R_{C}$ to $R_{T}$ remained around $0 \%$ on operating days $1-41$ and $81-141$ due 
to the fact that filtration conditions were sub-critical. This weighted average contribution increased sharply when operating at fluxes around or above the critical flux level (see operating days $61-81$ and $141-181$ ).

3.2. Model validation using lightly-fouled membranes

Lightly-fouled membranes were used for the validation of the model when operating at SRT of 71.5 days and $33^{\circ} \mathrm{C}$. Figure 4 a shows the average daily values of $J_{20 n e t}$ (approx. 8 and $11 \mathrm{LMH}$ ) and $\operatorname{SGD}_{\mathrm{m}}\left(0.23 \mathrm{Nm}^{3} \mathrm{~h}^{-1} \mathrm{~m}^{-2}\right)$ in this operating period. Figure $4 \mathrm{~b}$ shows the average daily values of $\mathrm{TMP}_{\text {SIM }}$ and TMP $\mathrm{EXP}_{\text {. Similar to the results }}$ obtained when operating using heavily-fouled membranes, Figure $4 \mathrm{~b}$ illustrates how the model was able to correctly reproduce long-term membrane performance operating under completely different conditions (lightly-fouled membranes) than in Figure $1 \mathrm{~b}$ (see Figure 4b), resulting in a Pearson's $r$ coefficient between TMP EXP and TMP SIM $_{\text {of }} 0.987$

Figure 5a shows the average daily MLTS level (ranging from 7 to $25 \mathrm{~g} \mathrm{~L}^{-1}$ ), and the simulated average daily values of $\omega_{C}$ and $\omega_{I}$. Using the $\mathrm{R}_{\mathrm{I}}$ determined experimentally as mentioned before, gave an initial $\omega_{I}$ of about $0.006 \mathrm{~kg}_{m_{I}} \mathrm{~m}^{-2}$ (see Figure 5a). In this case, Figure 5a shows how $\omega_{\mathrm{C}}$ increases as MLTS increases (a constant operating $J_{20 n e t}$ was maintained during the operating period, as, for instance, on operating days $57-141$ in Figure 4a). Similar to the results shown in Figure 2, this is due to the increasing convective transport of foulants $\left(X_{T S}\right.$ in the model) to the membrane surface caused by an increase in the bulk concentration. On the other hand, a significant increase in $\omega_{C}$ can be seen after operating day 130. As mentioned before, $q_{M S}$ is function of an exponential- 
type inhibition function that depends on both MLTS and $J_{20}$, which is used to model the effect of filtering at levels above or below critical conditions. Therefore, it can be assumed that the membranes were operated at near critical flux on operating days 131 141 (operating at $23 \mathrm{~g} \mathrm{~L}^{-1}$ of MLTS). Indeed, the critical flux was determined experimentally at these operating conditions $\left(23 \mathrm{~g} \mathrm{~L}^{-1}\right.$ of MLTS and SGD $\mathrm{m}$ of $0.23 \mathrm{Nm}^{3}$ $\mathrm{h}^{-1} \mathrm{~m}^{-2}$ ) giving a value of about 13.5 LMH, which coincides with the gross operating $J_{20}$ in this operating period.

As mentioned above, since the irreversible fouling rate is represented in the model as a direct function of $\omega_{C}$, a higher propensity to irreversible fouling was observed when operating at high $\omega_{C}$ values due to operating at high MLTS levels (see operating days $131-141$ in Figure 4a). In this respect, Figure 5a shows the highest irreversible fouling rate modelled in this operating period $\left(0.0004 \mathrm{~kg} X_{m_{I}} \mathrm{~m}^{-2} \mathrm{~d}^{-1}\right)$ that was reached on operating days $131-141$ (corresponding with the highest $\omega_{\mathrm{C}}$ levels). On the other hand, an irreversible fouling rate of $0.0001 \mathrm{~kg} X_{m_{I}} \mathrm{~m}^{-2} \mathrm{~d}^{-1}$ ) was modelled on operating days 1 - 131. The average irreversible fouling rate for the whole operating period (141 days of continuous operation) resulted in $0.00012 \mathrm{~kg} X_{m_{I}} \mathrm{~m}^{-2} \mathrm{~d}^{-1}$.

It must be said that similar overall irreversible fouling rates were observed in both operating periods: when operating at SRT of 71.5 days and $33^{\circ} \mathrm{C}\left(0.00015 \mathrm{~kg} X_{m_{I}} \mathrm{~m}^{-2}\right.$ $\left.\mathrm{d}^{-1}\right)$ and when operating at SRT of 38.5 days and $20{ }^{\circ} \mathrm{C}\left(0.00012 \mathrm{~kg} X_{m_{I}} \mathrm{~m}^{-2} \mathrm{~d}^{-1}\right)$. As mentioned before, this was mainly attributed to the presence of similar amounts of SMP and EPS in the mixed liquor (around $150-180 \mathrm{mg} \mathrm{g}^{-1}$ MLVS and $60-80 \mathrm{mg} \mathrm{g}^{-1}$ MLVS respectively), which resulted in similar propensities to irreversible fouling. Nevertheless, further research is required in the long term to establish the exact 
dependence of $q_{I F, \text { Max }}$ upon T and SRT.

The simulated average daily values for $\alpha_{C}$ were maintained from approx. $1.1 \cdot 10^{13}$ to $1.8 \cdot 10^{13} \mathrm{~m} \mathrm{~kg}^{-1}$ due to operating at low average TMP values (approx. $0.007-0.07$ bar) throughout the whole operating period ( $\alpha_{C}$ followed a similar behaviour to TMP).

Figure $5 \mathrm{~b}$ shows the simulated average daily results (in absolute terms) recorded in this operating period at the different filtration resistances considered in the model $\left(R_{T}\right.$, $R_{M}, R_{C}$ and $\left.R_{I}\right)$. Regarding reversible fouling, Figure 5b shows low $R_{C}$ values during the operating period resulting from the low values observed in $\omega_{C}$ and $\alpha_{C}$. Concerning irreversible fouling, Figure $5 \mathrm{~b}$ shows an increasing $R_{T}$ value due to an increasing $R_{I}$ value. The increase in $R_{I}$ is the result of the continuous modelled increase in $\omega_{I}$ (see Figure 5a). This behaviour highlights the necessity of modelling the irreversible fouling phenomenon in the long-term to account for the actual variation of $R_{T}$ over time. In this regard, a constant slightly increase in the weighted average contribution of $R_{I}$ to $R_{T}$ was observed throughout this operating period due to slightly increasing $\omega_{I}$ over time (see Figure 5a). On the other hand, the weighted average contribution of $R_{C}$ to $R_{T}$ remained around $0 \%$ until operating day 131 when sub-critical filtration conditions were applied.

Finally, it is important to highlight that the model was able to reproduce the filtration process in a SAnMBR system across a wide range of operating conditions when working with both lightly- and heavily-fouled membranes. These results illustrate the potential of the proposed model for predicting membrane performance in the long term. Therefore, because it was possible to simulate the long-term average daily weighted distribution of $R_{T}$ (including $R_{I}$ ), the proposed filtration model can indeed be used for the following objectives: to design and upgrade SAnMBR systems and to 
develop operating and control strategies designed to optimise the long-term performance of the process.

\section{Conclusions}

A filtration model has been validated in the long-term in an SAnMBR demonstration plant fitted with industrial-scale hollow-fibre membranes. The model was validated in a wide range of operating conditions using both heavily-fouled and lightlyfouled membranes. Model validation resulted in an adequate Pearson Product-Moment correlation coefficient $(r)$ between experimental and simulated data. The simulation results revealed that irreversible fouling is the main component in the weighted average distribution of total filtration resistance in the long term.

\section{Acknowledgements}

This research has been supported by the Spanish Ministry of Economy and Competitiveness (MINECO Project CTM2011-28595-C02-01/02) jointly with the European Regional Development Fund (ERDF), which are gratefully acknowledged.

\section{References}

[1] W. Naessens, T. Maere, I. Nopens, Critical review of membrane bioreactor models - Part 1: Biokinetic and filtration models, Bioresour. Technol. 122 (2012) 95 - 106.

[2] J. Ferrer, J.J. Morenilla, A. Bouzas, F. García-Usach, Calibration and simulation of two large wastewater treatment plants operated for nutrient removal, Water Sci. Technol. 50 (2004), 87 - 94.

[3] K. Derbal, M. Bencheikh-lehocine, F. Cecchi, A.-H. Meniai, P. Pavan, Application of the IWA ADM1 model to simulate anaerobic co-digestion of organic waste with waste activated sludge in 
mesophilic condition, Bioresour. Technol. 100 (2009), 1539 - 1543.

[4] M.V. Ruano, J. Serralta, J. Ribes, F. Garcia-Usach, A. Bouzas, R. Barat, A. Seco, J. Ferrer, Application of the General Model "Biological Nutrient Removal Model No.1" to upgrade two full-scale WWTPs, Environ. Technol. 33(2012), 1005 - 1012.

[5] G. Mannina, G. Di Bella, G. Viviani, An integrated model for biological and physical process simulation in membrane bioreactors (MBRs), J. Membrane Sci. 376 (2011), 56 - 69.

[6] A.N.L. Ng, A.S. Kim, A mini-review of modeling studies on membrane bioreactor (MBR) treatment for municipal wastewaters, Desalination 212 (2007), $261-281$.

[7] A. Robles, M.V. Ruano, J. Ribes, A. Seco, J. Ferrer, A filtration model applied to submerged anaerobic MBRs (SAnMBRs). J. Membrane Sci. (2013), J. Membrane Sci. 444(2013), 139 - 147.

[8] A. Robles, M.V. Ruano, J. Ribes, J. Ferrer, Factors that affect the permeability of commercial hollowfibre membranes in a submerged anaerobic MBR (HF-SAnMBR) system, Water Res. 47 (2013), 1277 1288.

[9] American Public Health Association/American Water Works Association/Water Environmental Federation, Standard methods for the Examination of Water and Wastewater, $21^{\text {st }}$ edition, Washington DC, USA, 2005.

[10] B. Frølund, R. Palmgren, K. Keiding, P.H. Nielsen, Extraction of extracellular polymers from activated sludge using a cation exchange resin, Water Res. 30 (1996) 1749 - 1758.

[11] M. Dubois, K.A. Gilles, J.K. Hamilton, P.A. Rebers, F. Smith, Colorimetric method for determination of sugar and related substances, Anal. Chem. 28 (1956) $350-356$.

[12] O.H. Lowry, N.J. Rosebrough, A.L. Farr, R.J. Randall, Protein measurement with the folin phenol reagent, J. Biol. Chem. 193 (1951) 265 - 275.

[13] T.V. Bugge, M.K. Jørgensen, M.L. Christensen, K. Keiding, Modeling cake buildup under TMP-step filtration in a membrane bioreactor: Cake compressibility is significant, Water Res. 46 (2012), 4330 4338.

[14] M.K. Jørgensen, T.V. Bugge, M.L. Christensen, K. Keiding, Modeling approach to determine cake buildup and compression in a high-shear membrane bioreactor, J. Membrane Sci. $409 / 410$ (2012), 335 345.

[15] M.L. Christensen, The Effect of Filter Cake Viscoelasticity on Filtration: a Study of Activated Sludge Dewatering, PhD thesis, Aalborg University, Department of Biotechnology, Chemistry and Environmental Engineering, Aalborg, Denmark, 2006. 
[16] LD. Hughes, R.W. Field, Crossflow filtration of washed and unwashed yeast suspensions at constant shear under nominally sub-critical conditions, J. Membr. Sci. 280 (2006), 89 - 98.

[17] M. Sarioglu, G. Insel, D. Orhon, Dynamic in-series resistance modeling and analysis of a submerged membrane bioreactor using a novel filtration mode, Desalination 285 (2012), 285 - 294.

[18] A. Robles, M.V. Ruano, F. García-Usach, J. Ferrer, Sub-critical filtration conditions of commercial hollow-fibre membranes in a submerged anaerobic MBR (HF-SAnMBR) system: The effect of gas sparging intensity, Bioresour. Technol. 114 (2012) 247-254.

[19] P. Le-Clech, V. Chen, T.A.G. Fane, Fouling in membrane bioreactors used in wastewater treatment, J. Membr. Sci. 284 (2006), 17 - 53.

[20] A. Robles, M.V. Ruano, J. Ribes, J. Ferrer, Performance of industrial scale hollow-fibre membranes in a submerged anaerobic MBR (HF-SAnMBR) system at mesophilic and psychrophilic conditions, Sep. Purif. Technol. 104 (2013), 290 - 296.

[21] F.G. Meng, S.R. Chae, A. Drews, M. Kraume, H.S. Shin, F.L. Yang, Recent advances in membrane bioreactors (MBRs): membrane fouling and membrane materials, Water Res. 43 (2009), 2405 - 2415. 


\section{Figure and table captions}

Figure 1. Long-term model validation using heavily-fouled membranes. Daily average values of: (a) $J_{20}$ and $\mathrm{SGD}_{\mathrm{m}}$; and (b) $\mathrm{TMP}_{\mathrm{EXP}}$ and $\mathrm{TMP}_{\mathrm{SIM}}{ }^{*}$ r represents the Pearson Product-Moment correlation coefficient between TMP ${ }_{E X P}$ and TMP $P_{S I M}$.

Figure 2. Long-term model validation using heavily-fouled membranes. Daily average values of: (a) MLTS, $\omega_{C}$ and $\omega_{I}$; and (b) $\alpha_{C}$.

Figure 3. Long-term model validation using heavily-fouled membranes. Daily average values of $R_{M}, R_{I}$, $R_{C}$ and $R_{T}$ in: (a) absolute terms $\left(\mathrm{m}^{-1}\right)$; and (b) weighted average distribution (\%).

Figure 4. Long-term model validation using lightly-fouled membranes. Daily average values of: (a) $J_{20}$ and $\mathrm{SGD}_{\mathrm{m}}$; and (b) $\mathrm{TMP}_{\mathrm{EXP}}$ and $\mathrm{TMP}_{\mathrm{SIM}}{ }^{*}$ r represents the Pearson Product-Moment correlation coefficient between TMP EXP and TMP SIM.

Figure 5. Long-term model validation using lightly-fouled membranes. Daily average values of: (a) MLTS, $\omega_{C}$ and $\omega_{I}$; and (b) $R_{M}, R_{I}, R_{C}$ and $R_{T}$.

Table 1. Stoichiometry and kinetic expressions of the processes considered in the model.

Table 2. Values for the different parameters included in the proposed filtration model. 


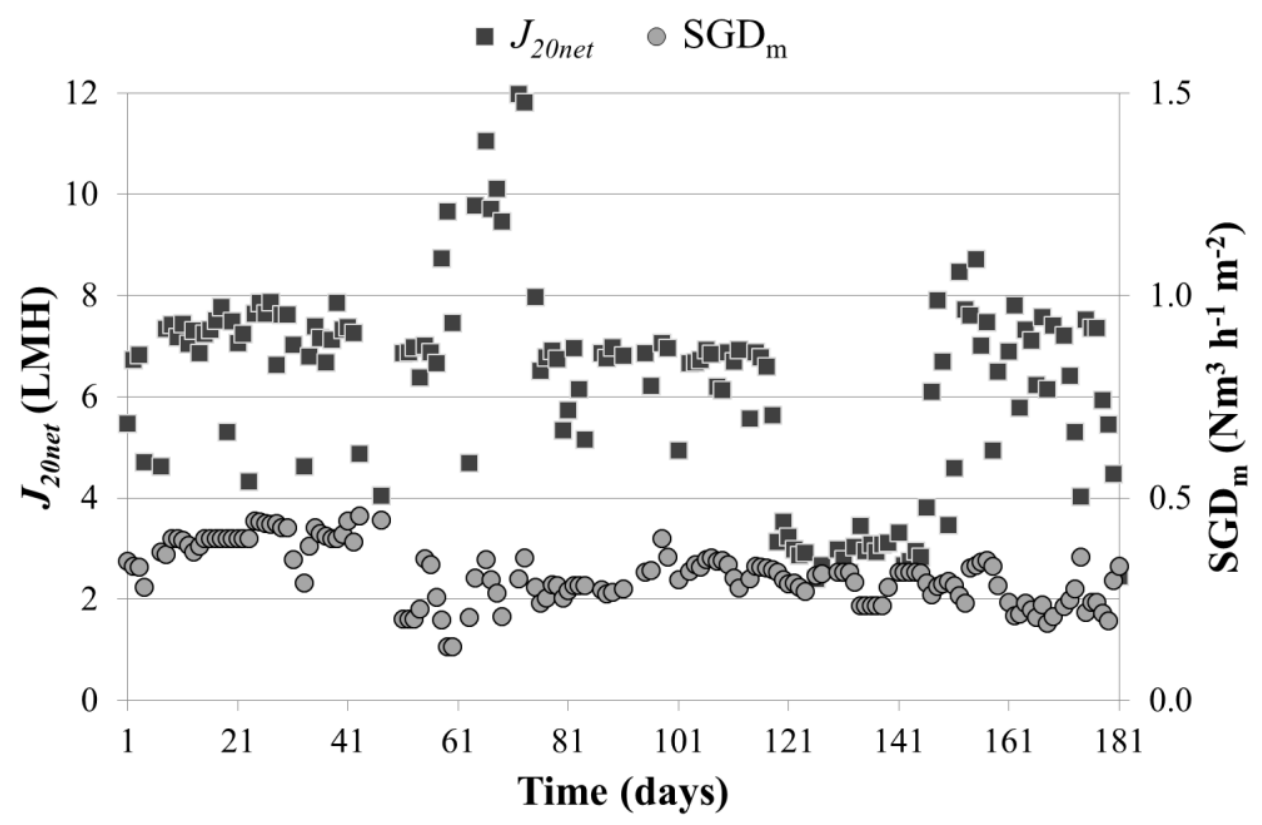

(a)

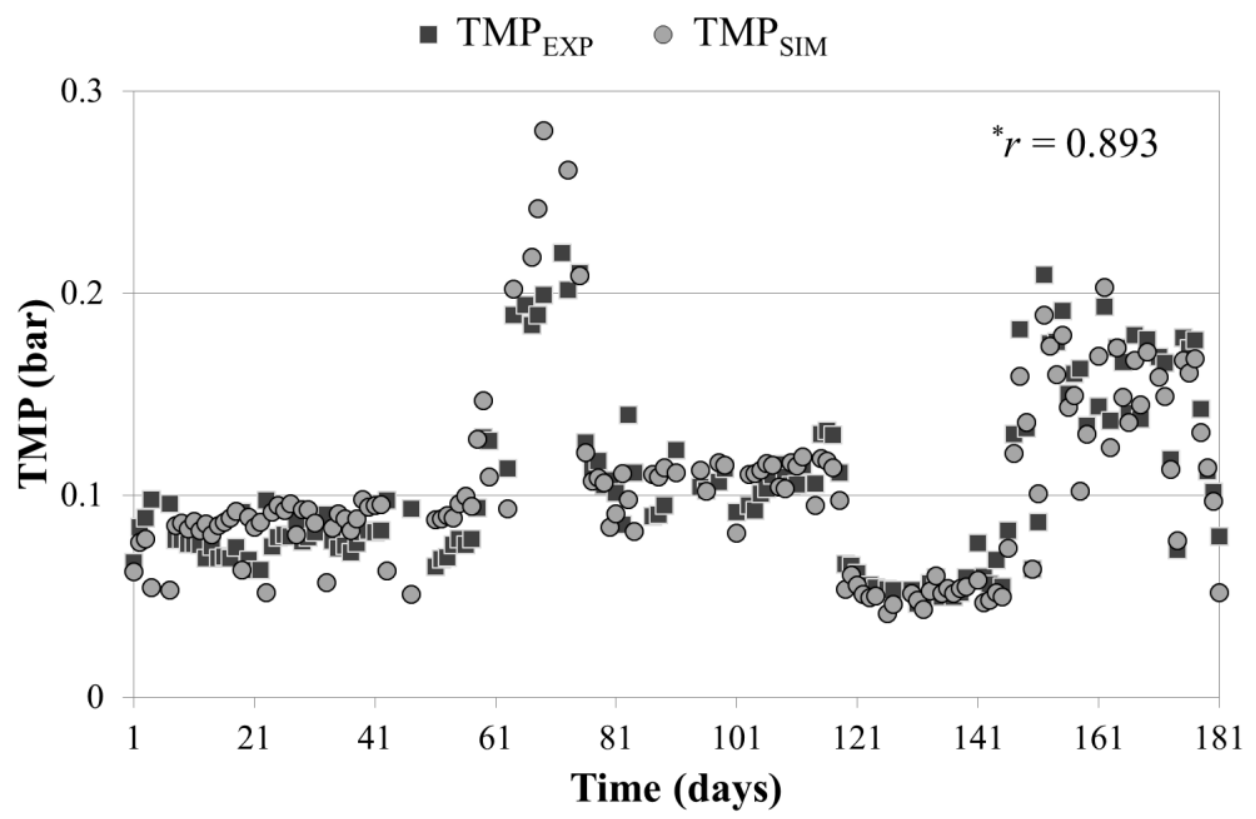

(b)

Figure 1. Long-term model validation using heavily-fouled membranes. Daily average values of: (a) $J_{20}$ and $\mathrm{SGD}_{\mathrm{m}}$; and (b) $\mathrm{TMP}_{\mathrm{EXP}}$ and $\mathrm{TMP}_{\mathrm{SIM}} \cdot{ }^{*}$ r represents the Pearson Product-Moment correlation coefficient between $T M P_{E X P}$ and $T M P_{S I M}$. 


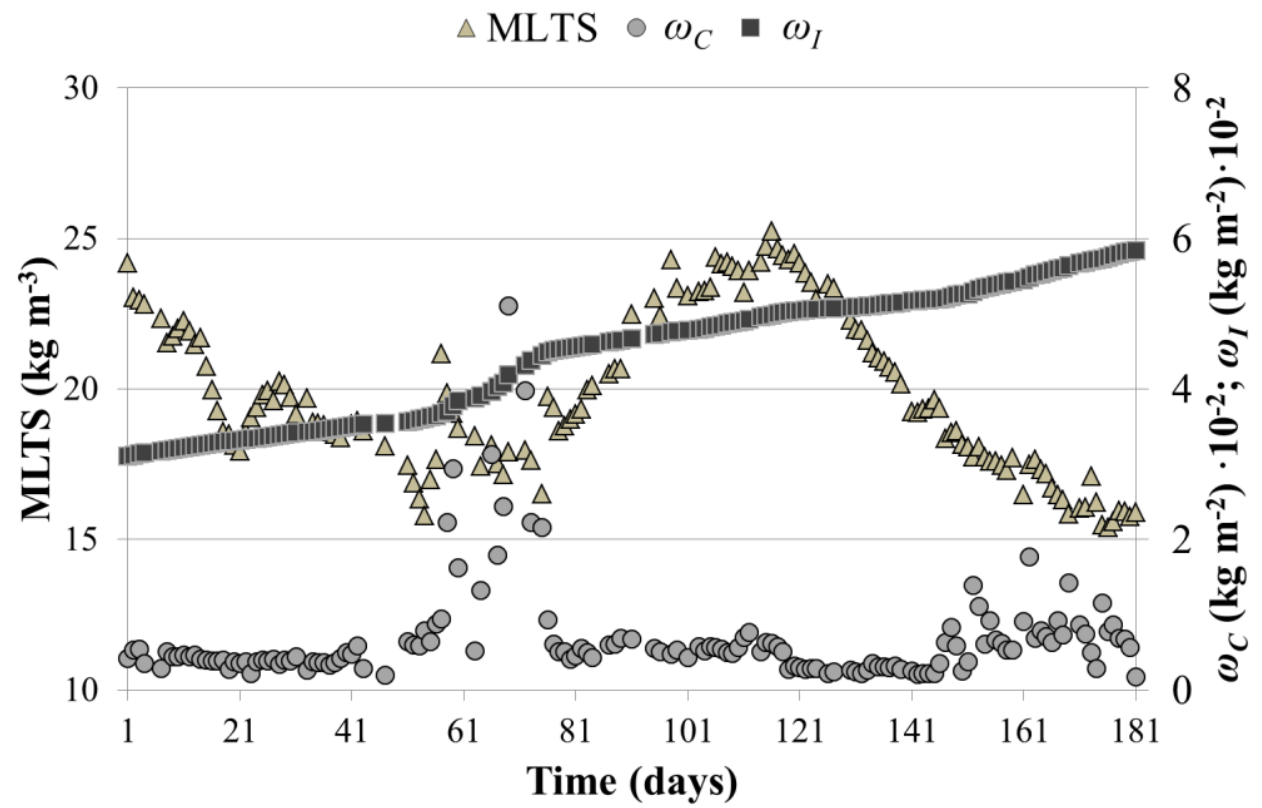

(a)

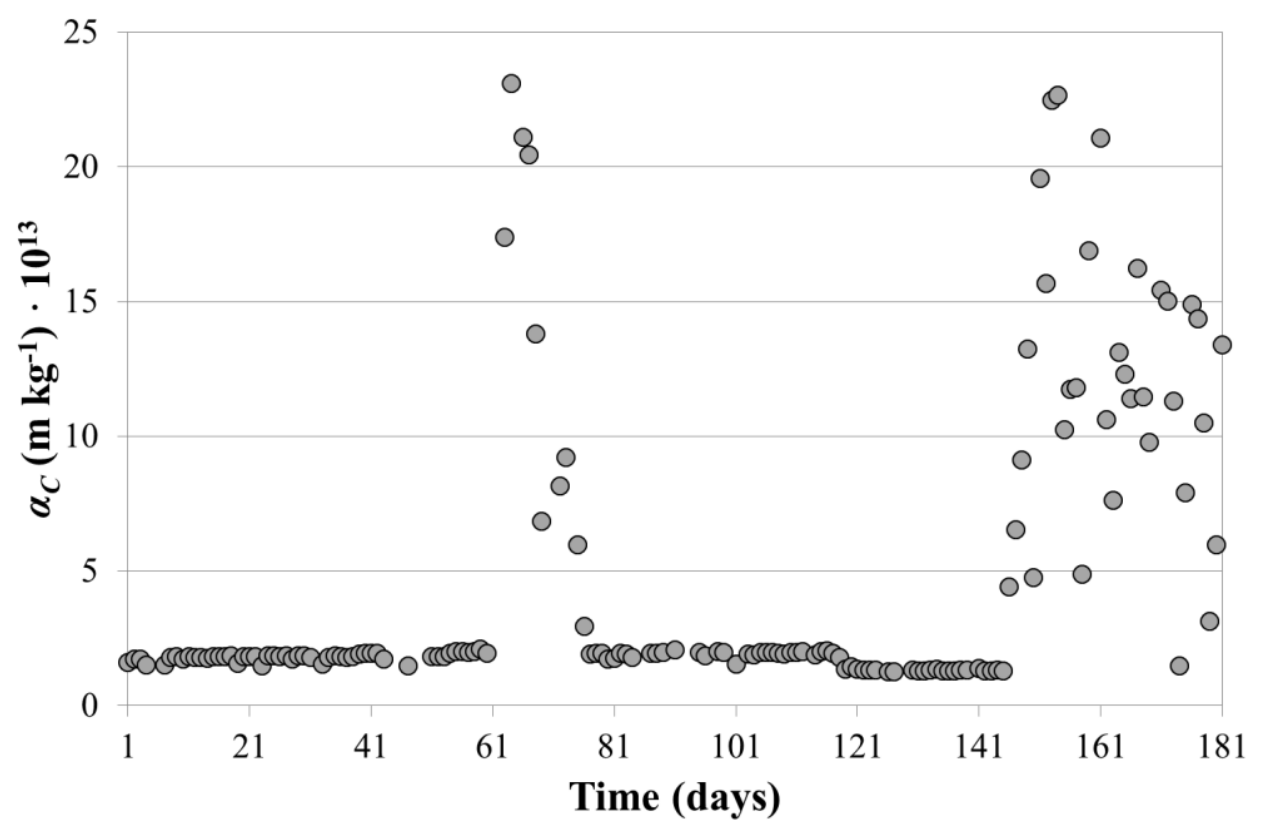

(b)

Figure 2. Long-term model validation using heavily-fouled membranes. Daily average values of: (a) MLTS, $\omega_{C}$ and $\omega_{I}$; and (b) $\alpha_{C}$. 


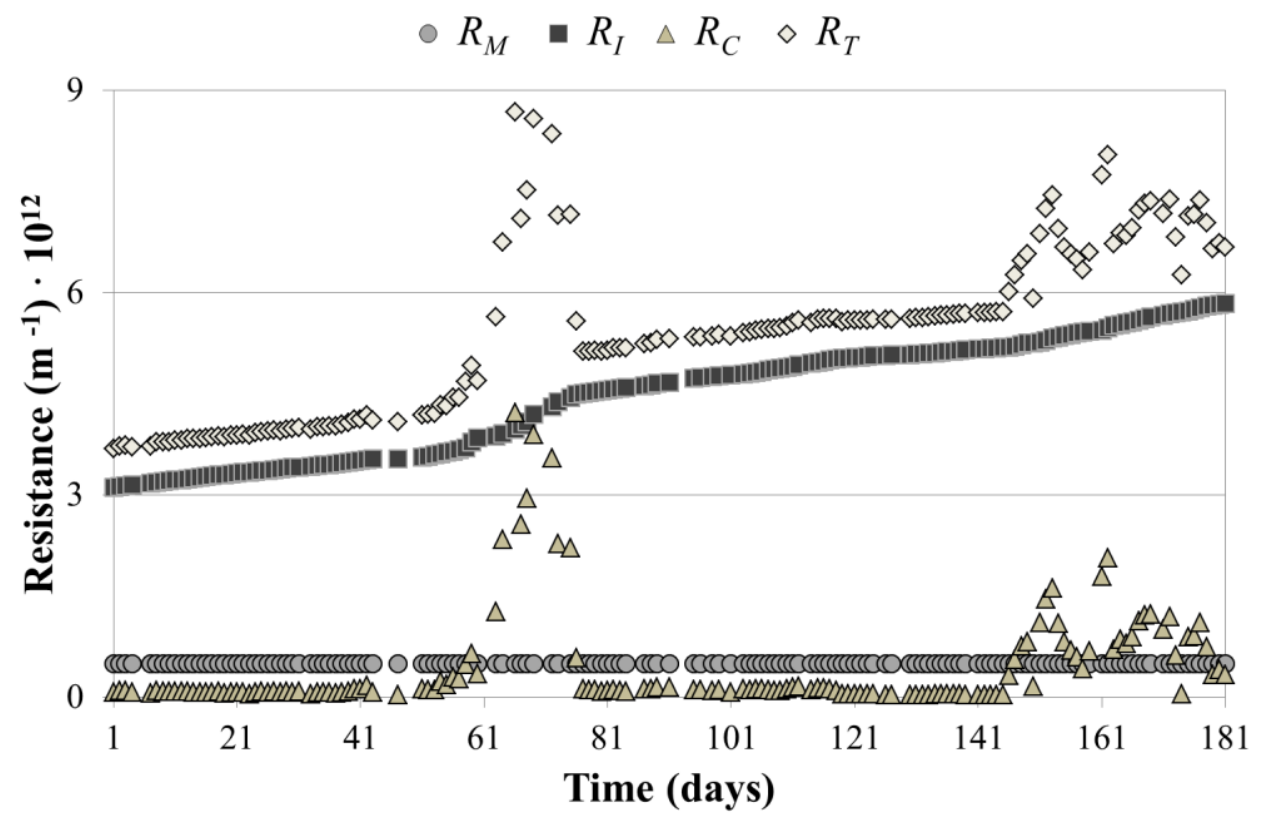

(a)

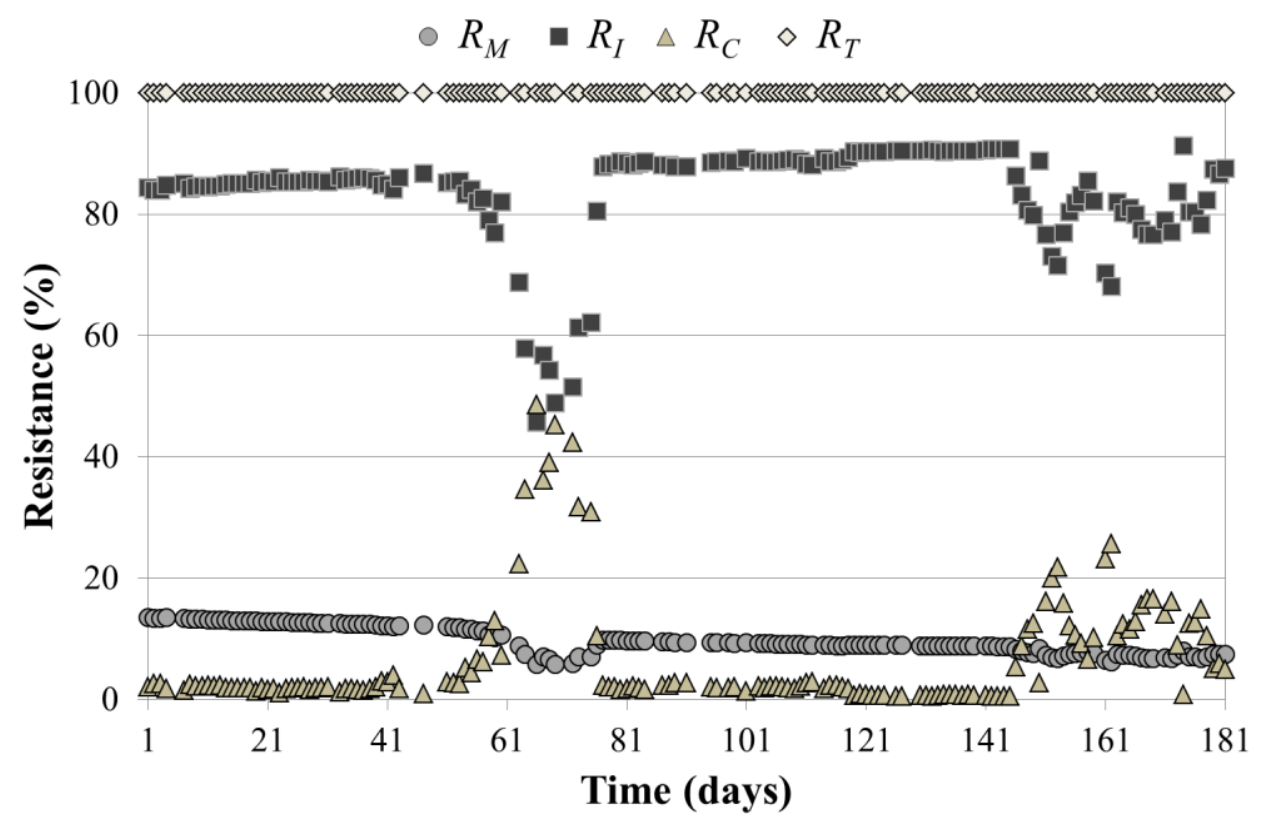

(b)

Figure 3. Long-term model validation using heavily-fouled membranes. Daily average values of $R_{M}, R_{I}$,

$R_{C}$ and $R_{T}$ in: (a) absolute terms $\left(\mathrm{m}^{-1}\right)$; and (b) weighted average distribution (\%). 


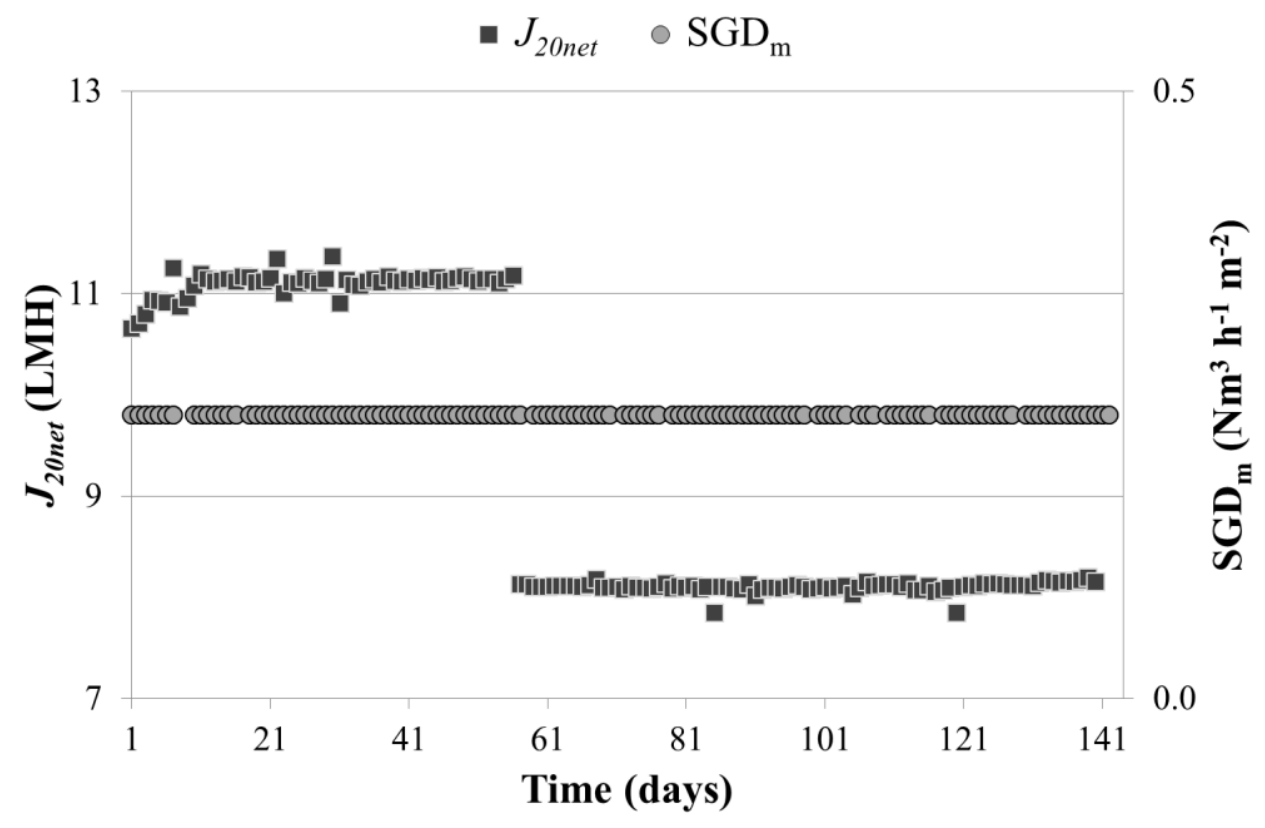

(a)

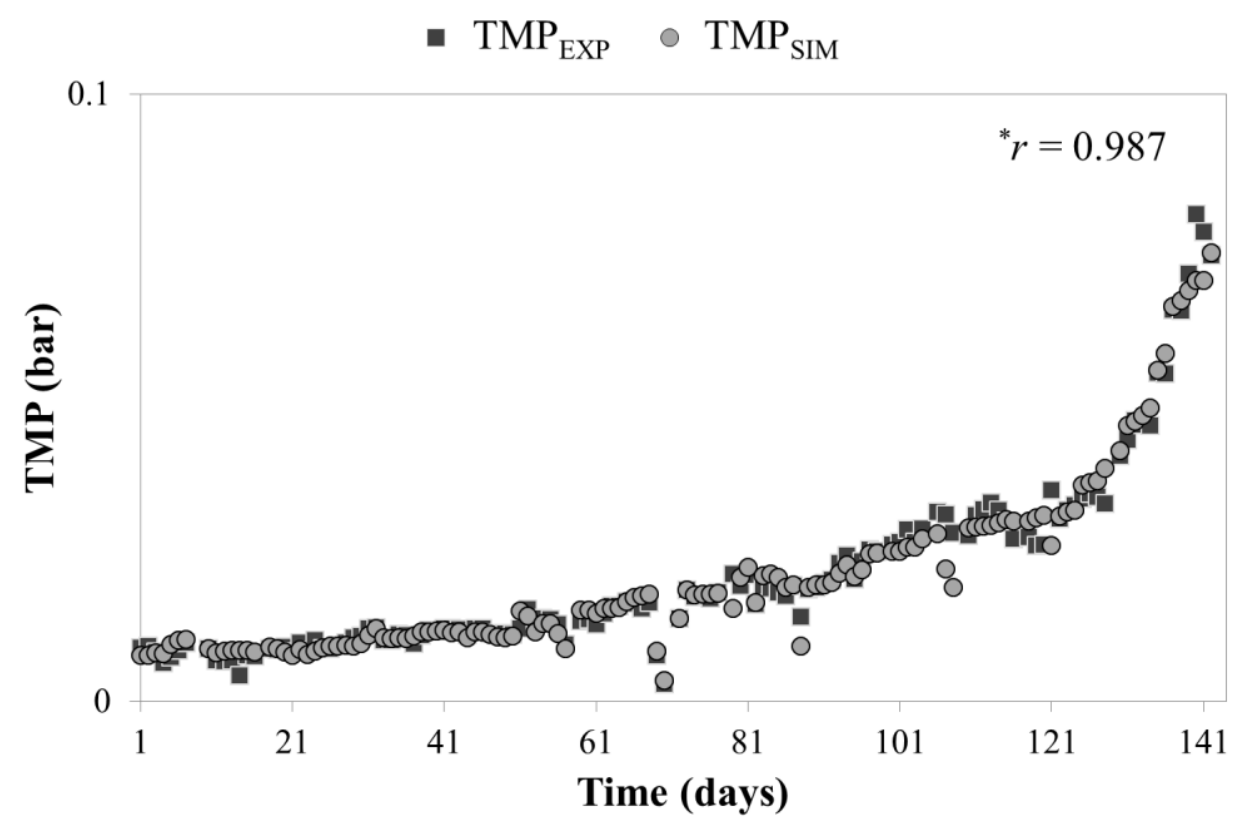

(b)

Figure 4. Long-term model validation using lightly-fouled membranes. Daily average values of: (a) $J_{20}$ and $\mathrm{SGD}_{\mathrm{m}}$; and (b) $\mathrm{TMP}_{\mathrm{EXP}}$ and $\mathrm{TMP}_{\mathrm{SIM}} \cdot{ }^{*} r$ represents the Pearson Product-Moment correlation coefficient between $T M P_{E X P}$ and $T M P_{S I M}$. 


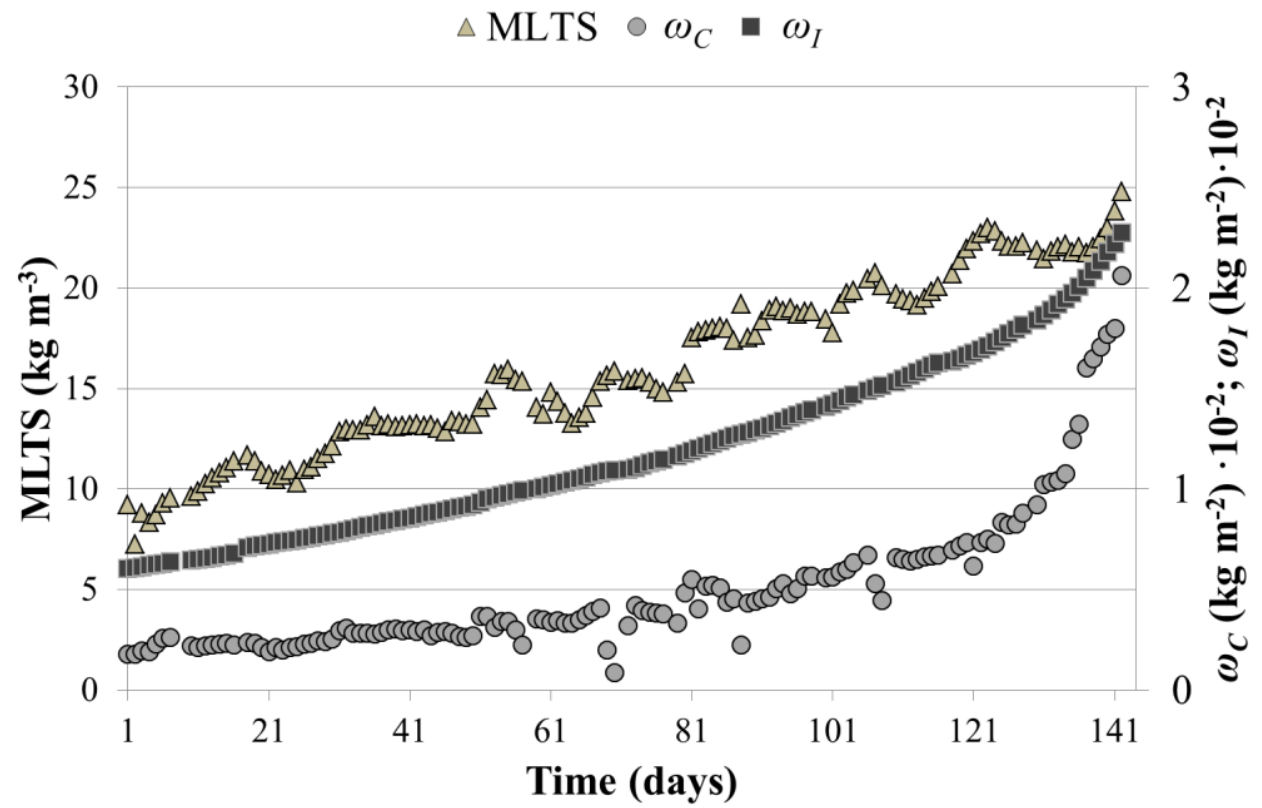

(a)

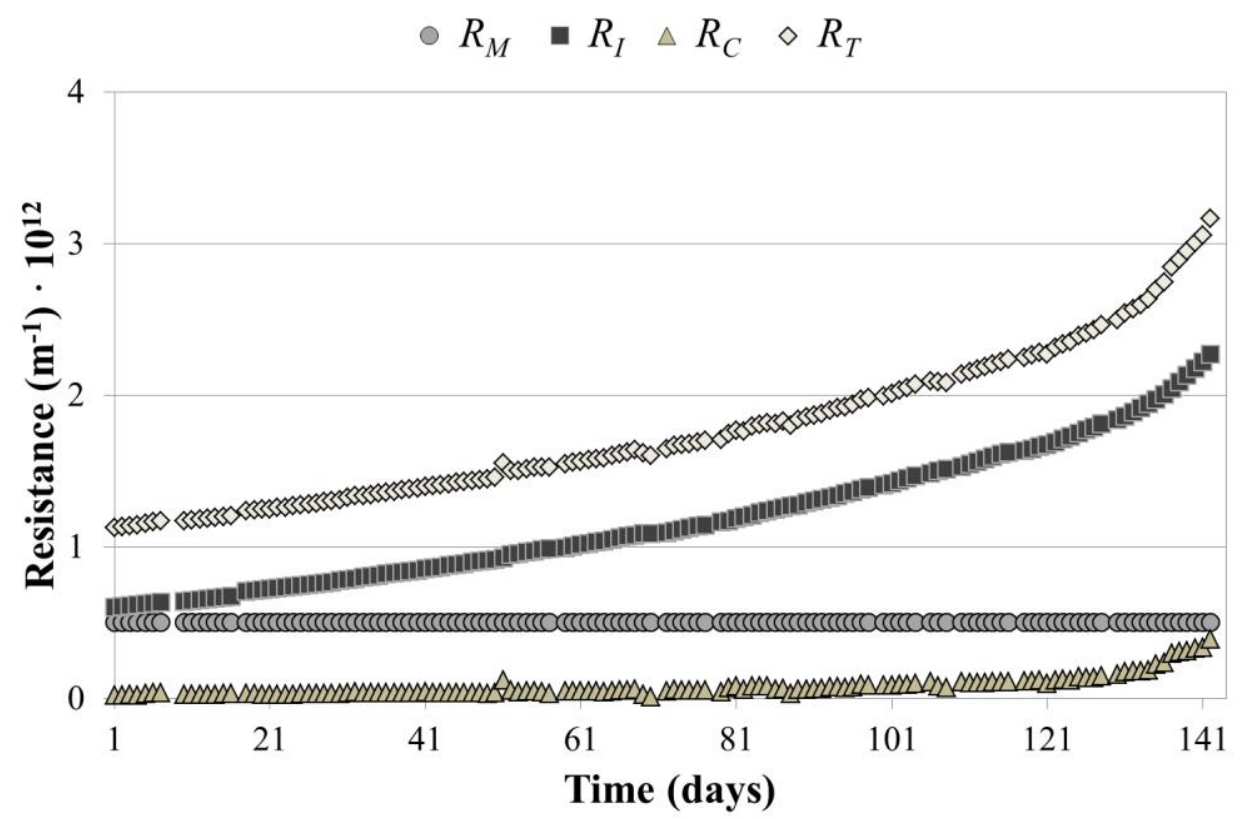

(b)

Figure 5. Long-term model validation using lightly-fouled membranes. Daily average values of: (a) MLTS, $\omega_{C}$ and $\omega_{I}$; and (b) $R_{M}, R_{I}, R_{C}$ and $R_{T}$. 
Table 1. Stoichiometry and kinetic expressions for the processes considered in the model.

\begin{tabular}{lcccl}
\hline j Process & $X_{T S}$ & $X_{m_{C}}$ & $X_{m_{I}}$ & Kinetic expression \\
\hline $\begin{array}{l}\text { 1. Cake layer formation } \\
\begin{array}{l}\text { 2. Membrane scouring by } \\
\text { biogas }\end{array}\end{array}$ & -1 & 1 & & $Q_{20 P} \cdot X_{T S}$ \\
$\begin{array}{l}\text { 3. Cake layer detachment } \\
\text { during back-flushing }\end{array}$ & 1 & -1 & & $q_{M S, M a x} \cdot M_{X_{m_{C}}} \cdot I_{M S} \cdot B R F_{V} \cdot X_{m_{C}}$ \\
$\begin{array}{l}\text { 4. Irreversible fouling } \\
\text { consolidation }\end{array}$ & & -1 & & $q_{B F, M a x} \cdot Q_{20 B F} \cdot M_{X_{m_{C}}} \cdot X_{m_{C}}$ \\
\hline
\end{tabular}


Table 2. Values for the different parameters included in the proposed filtration model.

\begin{tabular}{lll}
\hline Parameter & Units & Value \\
\hline$q_{M S, M a x}$ & & 6.31 \\
$q_{B F, \text { Max }}$ & $\mathrm{m}^{-3}$ & 1 \\
$q_{I F, \text { Max }}$ & $\mathrm{s}^{-1}$ & $3 \cdot 10^{-07}$ \\
$K_{S, X_{m_{C}}}$ & $\mathrm{~kg}_{m_{C}}$ & 0.2 \\
$\alpha_{C, 0}$ & $\mathrm{~m} \mathrm{~kg}^{-1}$ & $1.02 \cdot 10^{13}$ \\
$T M P_{a}$ & $\mathrm{kPa}$ & 18.9 \\
$k_{t}$ & $\mathrm{~s}^{-1}$ & 1 \\
$k_{S F}$ & $\mathrm{~m} \mathrm{~kg}^{-1} \mathrm{~s}^{-1}$ & $4.09 \cdot 10^{10}$ \\
$K_{F}$ & $\mathrm{~Pa} \mathrm{~s}^{-1}$ & $5.6 \cdot 10^{-4}$ \\
$\beta_{I}$ & $\mathrm{~s}^{2} \mathrm{~m}^{-1}$ & $-2.48 \cdot 10^{8}$ \\
$\beta_{2}$ & $\mathrm{~s} \mathrm{~m}^{2} \mathrm{~kg}^{-1}$ & $5.1 \cdot 10^{4}$ \\
$\gamma_{0}$ & $\mathrm{~s} \mathrm{~m}^{-1}$ & $2.81 \cdot 10^{6}$ \\
$k_{R I}$ & $\mathrm{~s}$ & $1.6 \cdot 10^{-07}$ \\
$\alpha_{I}$ & $\mathrm{~m} \mathrm{~kg}^{-1}$ & $1 \cdot 10^{14}$ \\
\hline
\end{tabular}

